\title{
Response to Mavridis' area as a target for either selective or combined accumbens/ventral internal capsule deep brain stimulation
}

\author{
Pepijn van den Munckhof • P. Richard Schuurman
}

Received: 14 November 2014 / Accepted: 18 November 2014 / Published online: 30 November 2014

(C) Springer-Verlag Wien 2014

\section{Dear editor,}

We would like to thank Dr. Mavridis for his interest in our article [2]. The results of our study indicate that deep brain stimulation (DBS) electrodes in patients with therapyrefractory obsessive-compulsive disorder (OCD) should not be targeted in the grey matter of the nucleus accumbens but in the white matter tracts of the ventral part of the anterior limb of the internal capsule (vALIC). Indeed, none of the 16 studied patients reported any clinical improvement while receiving stimulation at the two ventral DBS contacts (i.e. contacts 0 and $1)$, which were located in the nucleus accumbens. Since voltage increments up to 6 volts were used, Mavridis' area was also within this clinically ineffective ventral field of stimulation. Clinical improvement began only after switching DBS to the two dorsal contacts (i.e. contacts 2 and 3), which were located in the vALIC. The vALIC harbours white matter tracts of the cortical-striatal-thalamic-cortical (CSTC) circuit, which' hyperactivity is known to be associated with OCD [1]. Based on the results of our study, we have changed the current targeting strategy in OCD patients undergoing DBS: instead of implanting DBS electrodes with a coronal angle approximately following the ALIC into the NAc, we now implant them with a coronal angle exactly following the ALIC, and with contacts 1 and 2 in vALIC just posterior of the ventral caudate/ventral striatum. Of course, one could hypothesise that the most dorsal contacts of DBS electrodes targeted at Mavridis' area are also capable of delivering a clinically effective field of stimulation in vALIC. But since DBS of white matter tracts in vALIC seems the key to success in OCD DBS, we prefer DBS nomenclature that specifies this latter anatomical area.

Conflict of interest The Department of Neurosurgery of the AMC has received an unrestricted grant for movement disorders research from Medtronic. Dr Schuurman has received travel grants from Medtronic and acts as an independent advisor for Medtronic on educational matters.

\section{References}

1. Greenberg BD, Rauch SL, Haber SN (2010) Invasive circuitry-based neurotherapeutics: stereotactic ablation and deep brain stimulation for OCD. Neuropsychopharmacology 35:317-336

2. Van den Munckhof P, Bosch DA, Mantione MH, Figee M, Denys DA, Schuurman PR (2013) Active stimulation site of nucleus accumbens deep brain stimulation in obsessive-compulsive disorder is localized in the ventral internal capsule. Acta Neurochir Suppl 117:53-59
P. van den Munckhof $(\bowtie) \cdot$ P. R. Schuurman

Department of Neurosurgery, Academic Medical Center, University

of Amsterdam, Meibergdreef 9, 1005 AZ Amsterdam, The

Netherlands

e-mail: p.vandenmunckhof@amc.nl 